
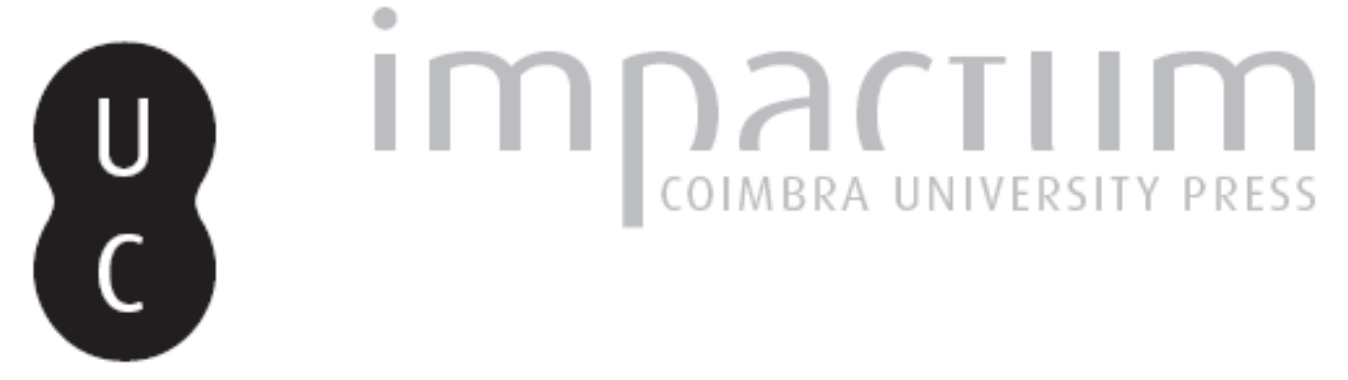

\title{
Desafios metodológicos no estudo da relação das crianças com as notícias: o recurso a metodologias participativas na dinamização de grupos de foco
}

Autor(es): $\quad$ Silveira, Patrícia

Publicado por: Imprensa da Universidade de Coimbra

URL persistente:

URI:http://hdl.handle.net/10316.2/38140

DOI:

DOI:http://dx.doi.org/10.14195/2183-5462_27_3

Accessed : $\quad$ 26-Apr-2023 15:17:10

A navegação consulta e descarregamento dos títulos inseridos nas Bibliotecas Digitais UC Digitalis, UC Pombalina e UC Impactum, pressupõem a aceitação plena e sem reservas dos Termos e Condições de Uso destas Bibliotecas Digitais, disponíveis em https://digitalis.uc.pt/pt-pt/termos.

Conforme exposto nos referidos Termos e Condições de Uso, o descarregamento de títulos de acesso restrito requer uma licença válida de autorização devendo o utilizador aceder ao(s) documento(s) a partir de um endereço de IP da instituição detentora da supramencionada licença.

Ao utilizador é apenas permitido o descarregamento para uso pessoal, pelo que o emprego do(s) título(s) descarregado(s) para outro fim, designadamente comercial, carece de autorização do respetivo autor ou editor da obra.

Na medida em que todas as obras da UC Digitalis se encontram protegidas pelo Código do Direito de Autor e Direitos Conexos e demais legislação aplicável, toda a cópia, parcial ou total, deste documento, nos casos em que é legalmente admitida, deverá conter ou fazer-se acompanhar por este aviso.

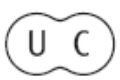




\section{Mediag Ornalismo}

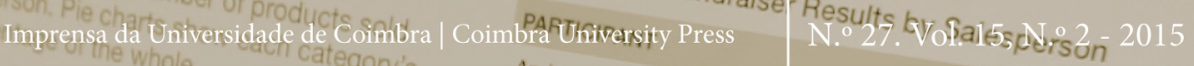

\section{U.m

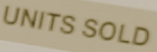 \\ EDUCÂÇÃO PARA OS}

MEDIA NA ERA DIGITAL
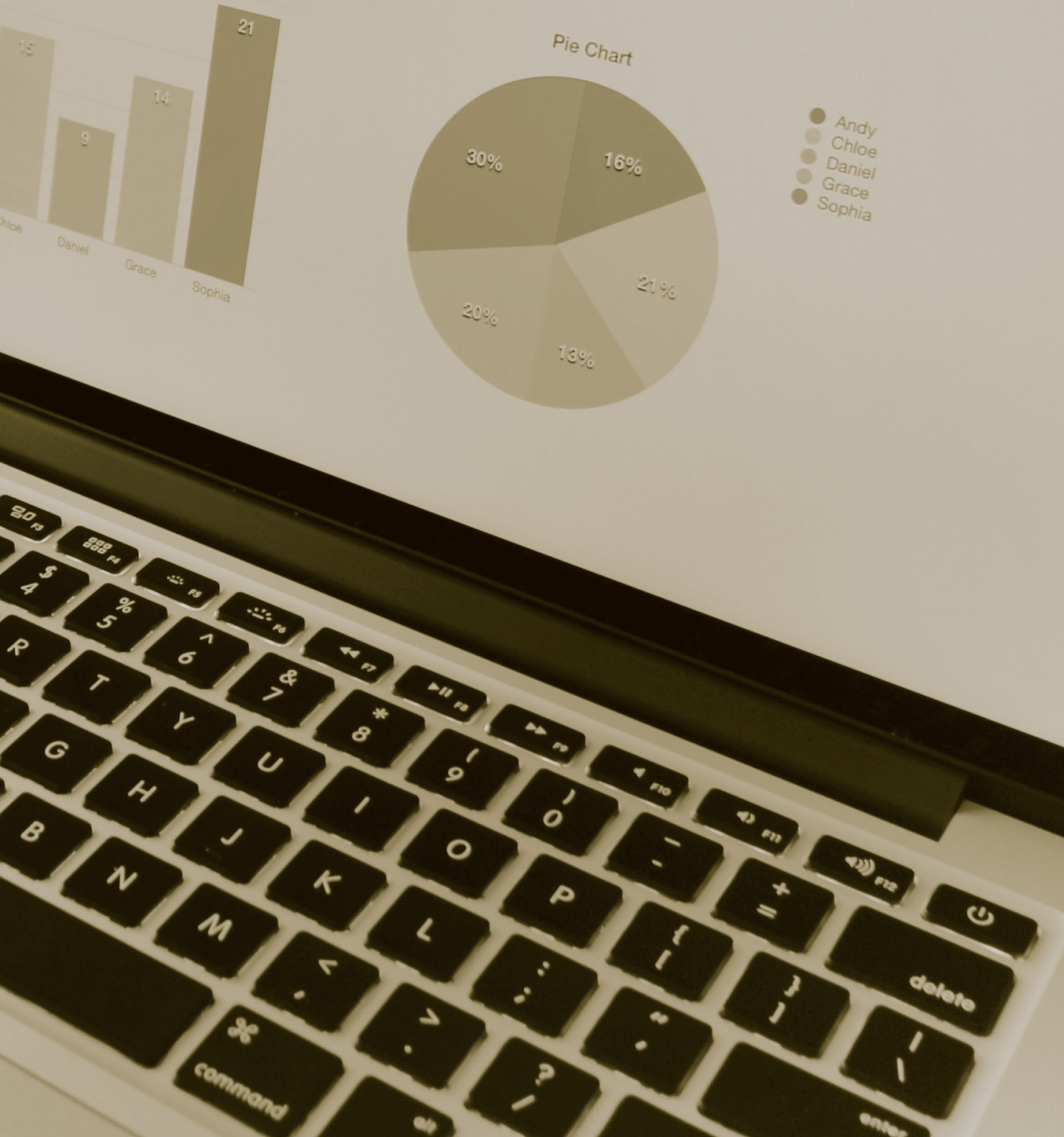


\title{
DESAFIOS METODOLÓGICOS NO ESTUDO DA RELAÇÃO \\ DAS CRIANÇAS COM AS NOTÍCIAS: \\ 0 RECURSO A METODO LOGIAS PARTICIPATIVAS \\ NA DINAMIZAÇÃO DE GRUPOS DE FOCO \\ METHODOLOGICAL CHALLENGES IN THE STUDY \\ OF CHILDREN'S RELATIONSHIP WITH THE NEWS: \\ THE USE OF PARTICIPATORY METHODOLOGIES \\ IN LEADING FOCUS GROUPS
}

\author{
PATRÍCIA SILVEIRA \\ ANA_DA_SILVEIRA@HOTMAIL.COM \\ CENTRO DE ESTUDOS DE COMUNICAÇÃO E SOCIEDADE (CECS), \\ UNIVERSIDADE DO MINHO
}

\begin{abstract}
Resumo
Este estudo pretende apresentar a opção e o procedimento metodológico de uma tese de doutoramento em curso, que tem como objeto de estudo as crianças e as suas representações sobre a atualidade e o mundo. Partindo de um referencial teórico que se apoia na sociologia da infância, defendemos a ideia de criança como indivíduo competente e criativo na construção de significados sobre a realidade, e como interveniente do processo investigativo. Em simultâneo, entendemos as notícias como importantes referentes para o modo como a criança conhece 0 mundo, considerando que é fundamental que esta desenvolva competências de literacia mediática face à informação. Com base nestes pressupostos, damos conta do recurso a metodologias participativas na dinamização de grupos de foco com crianças, com o propósito de as colocar numa relação autónoma e criativa com as notícias, com vista ao desenvolvimento de posturas críticas face aos modos de olhar o mundo propostos pelos media.
\end{abstract}

\section{Palavras-chave}

Crianças, atualidade, literacia para as notícias, direitos de participação, metodologias participativas.

Abstract

This paper intends to present the methodological procedure of an ongoing $\mathrm{PhD}$ research, whose study object is the children and their representations about current events and the world. From a theoretical framework that builds on the sociology of childhood, we support the idea of child as competent and creative in the construction of their own meanings about reality and as subjects of the research process. At the same time, we look at news media as an important reference to the ways children know the world, considering that it is essential that they develop news literacy skills. Based on these assumptions, we use the account to participatory me- 
thods in leading focus groups with children, in order to put them in an autonomous and creative relationship with current events and to enable them to adopt a critical stance about the ways of understanding the world proposed by the media.

KEYWORDS

Children, current events, news literacy, participation rights, participatory methods. 


\title{
DESAFIOS METODOLÓGICOS NO ESTUDO DA RELAÇÃO \\ DAS CRIANÇAS COM AS NOTÍCIAS: \\ O RECURSO A METODOLOGIAS PARTICIPATIVAS \\ NA DINAMIZAÇÃO DE GRUPOS DE FOCO
}

\author{
PATRÍCIA SILVEIRA \\ ANA_DA_SILVEIRA@HOTMAIL.COM \\ CENTRO DE ESTUDOS DE COMUNICAÇÃO E SOCIEDADE (CECS), \\ UNIVERSIDADE DO MINHO
}

\section{Introdução}

Os estudos sobre os mundos das crianças têm problematizado a entrada de novos agentes de socialização, nomeadamente dos meios de comunicação, no quotidiano dos mais novos. Estes estudos dizem que os media e as suas mensagens são tão importantes para a vida das crianças que acabam por concorrer com as agências e instituições tradicionais, como a família e a escola (Lazo, 2005; Setton, 2002). Embora estes contextos continuem a ser fundamentais para o desenvolvimento da criança e o modo como esta cria conhecimento sobre o mundo, há autores que defendem que os media interferem diretamente nos modos de compreensão da realidade pelas crianças (Lacave, 2011), desempenhando um importante papel na transmissão de normas e valores a que, de outro modo, estas dificilmente teriam acesso (Galera \& Pascual, 2005).

Neste contexto, os conteúdos informativos ganham especial destaque ao constituírem-se como veículos dos acontecimentos e importantes auxiliares da interpretação do mundo. Ainda que esta influência não se dê toda da mesma forma e dependa, também, de outros fatores, como as negociações entre as crianças e a família, (Buijzen et al., 2007), as condições circunstanciais, as necessidades dos mais novos, e os valores e costumes adquiridos (Galera, 2000), é inegável que as notícias são importantes mediadoras no contato das crianças com os acontecimentos do mundo. Estudos recentes demonstram que a atualidade faz parte da vida das crianças e que estes públicos entendem que 0 acesso às notícias é fundamental, procurando estes conteúdos para estar a par de assuntos relacionados com política internacional, novas descobertas científicas, conflitos armados, desporto, crimes, etc. (Condeza et al., 2014). Além disso, as crianças reconhecem que as estórias expostas nas notícias são relevantes para a sociedade e indispensáveis para a tomada de decisões e a formação de opinião sobre assuntos públicos (Alon-Tirosh \& Lemish, 2014; Carter et al., 2009).

Estas questões levam os autores (Thoman \& Jolls, 2004; Gonnet, 2007; Buckingham, 2000) a sublinhar a necessidade de as crianças desenvolverem competências críticas face às notícias e aos modos de olhar o mundo propostos pelos media. Considerando que estes funcionam como mecanismos relevantes para a compreensão de aspetos da realidade e a ampliação de um conjunto de saberes, observam que é fundamental que os públicos infantis, desde cedo, possam refletir sobre e questio- 
nar os valores e princípios transmitidos, assim como aspetos mais técnicos, como as opções editoriais, por exemplo, e os modos de funcionamento das empresas mediáticas. Além disso, advogam que é necessário que os mais novos tenham oportunidade para aprender a distinguir factos de ficção, e para desenvolver as suas próprias ideias sobre verdade e informação credível, desenvolvendo competências de literacia para as notícias de modo a tornarem-se públicos mais competentes.

A relação que as crianças estabelecem com as notícias e a importância destes assuntos para 0 seu conhecimento do mundo e a socialização têm vindo a ser alvo de estudo de investigadores de áreas distintas, tendo aumentado o número de pesquisas em torno desta problemática (Alon-Tirosh \& Lemish, 2014; Condeza et al., 2014; Marôpo, 2014). Nestas investigações, há autores (Alon-Tirosh \& Lemish, 2014; Carter et al., 2009) que sublinham a necessidade de compreender a importância do lugar dos media e da atualidade na vida das crianças, a partir das perspetivas destes públicos, considerando as suas ideias e opiniões, dando-lhes, assim, um lugar privilegiado no processo investigativo. Estes estudos, apoiados também na sociologia da infância, rompem com pressupostos clássicos defensores da ideia de criança como reprodutora do mundo adulto e parte integrante de outros objetos de estudo (como a família). Perspetivam a ideia de criança como criadora da sua própria cultura, realidade e experiência (Moinian, 2009) e defendem um novo posicionamento das crianças nos estudos que incorpore as suas vozes sobre as experiência de vida, entendendo-as como parceiras e sujeitos de todo o processo (Janzen, 2008).

Todas estas questões colocam desafios aos investigadores das ciências sociais, que necessitam de desenvolver metodologias que permitam chegar mais perto do olhar e das experiências das crianças, dando-Ihes espaço para participarem ativamente no processo de investigação. É nesta preocupação, e na intenção de partilhar a experiência de um estudo qualitativo conduzido junto dos mais novos, que este artigo assenta. Tendo por base um marco teórico que parte, sobretudo, da sociologia da infância, visa dar conta da opção e do procedimento metodológico levado a cabo no âmbito de uma investigação de doutoramento, em curso no Centro de Estudos de Comunicação e Sociedade (CECS) da Universidade do Minho, que tem como objeto de estudo os públicos infantis e as suas representações sobre as notícias. Uma das fases do trabalho empírico compreendeu a realização de grupos de foco junto de crianças a frequentar a escola primária; no entanto, a consciência de que a opção pela forma clássica de conduzir estes grupos junto de crianças pequenas não seria a desejável e poderia comprometer a recolha dos dados e a qualidade da investigação levou à opção por novas estratégias de investigação designadas "atividades estruturadas" (Gibson, 2012, p.157), como forma de dinamização dos grupos de foco e com vista a um maior envolvimento dos participantes. A apresentação e a descrição dessas atividades, assim como do modo como decorreu a dinâmica dos grupos, são o principal foco de atenção deste artigo.

\section{A criança como sujeito-ativo no processo de investigação}

Nos últimos anos, tem crescido o número de estudos sobre os mecanismos ligados ao processo de socialização das crianças e a influência de novos agentes - como os media e os seus conteúdos - nas suas vidas e nos modos de entendimento do mundo (Ladavéze, 2012; Kotilainen, 2011; Richert et al., 2011; Lazo, 2005). Estes tra- 
balhos abrem caminho a novas investigações que perspetivam a ideia de construção social da infância e de criança como co-construtora de conhecimento, identidade e cultura (Janzen, 2008), reelaborando o conceito face à visão ocidental e adultocêntrica da criança. Hoje fala-se na reinstitucionalização da infância, assistindo-se a novos modos de ser criança como resultado de mudanças e ruturas sociais complexas de âmbito económico, familiar, escolar e cultural (Sarmento, 2004).

0 entendimento da criança como ator social e sujeito de forças e competências emerge, sobretudo, como resultado do desenvolvimento nos estudos da sociologia da infância e das teorias socioculturais, e da implementação da Convenção sobre os Direitos da Criança (CDC) aprovada pela Assembleia Geral das Nações Unidas a 20 de Novembro de 1989 (Graham e Fitzgerald, 2010). No âmbito dos direitos legitimados por esta Convenção, importa fazer referência aos direitos de participação que são os direitos civis e políticos, nomeadamente, ao nome e à identidade, a ser consultada e ouvida, a aceder à informação e a ser informada, à liberdade de expressão e opinião, e à tomada de decisões em seu proveito (artigos 12. ${ }^{\circ}, 13 .{ }^{\circ}, 14 .{ }^{\circ}$, $15^{\circ}, 17 .{ }^{\circ}$ da $\mathrm{CDC}$ ). Estes últimos dão legitimidade às crianças para decidirem por si (Fernandes, 2005, p. 35), sendo "reconhecidas como seres independentes e afirmativos, agentes da própria vida" (Marôpo, 2013, p. 17). A introdução dos direitos de participação na legislação e no debate público e político fez reacender a necessidade de se olhar para as crianças como pessoas com um certo grau de autodeterminação, com o direito de expressarem as suas opiniões e pontos de vista sobre todas as questões que thes dizem respeito, de acordo com a sua idade e maturidade cognitiva. Neste contexto, 0 artigo $12 .^{\circ}$ da CDC é muito importante, uma vez que insiste na visibilidade da criança, reconhecendo o seu estatuto na sociedade, sem no entanto desvalorizar a necessidade de adultos e crianças colaborarem com vista à efetivação do reconhecimento e do exercício dos direitos destas. Este artigo prevê que a criança possa formar e expressar livremente os seus pontos de vista em matérias que Ihe dizem respeito de acordo com a sua maturidade e entendimento dos assuntos. 0 artigo 13. ${ }^{\circ}$ da CDC é, também, fundamental neste domínio, já que prevê 0 direito à liberdade de expressão, considerando que "a criança tem o direito de exprimir os seus pontos de vista, obter informações, dar a conhecer ideias e informações, sem considerações de fronteiras".

Um dos passos importantes no reconhecimento destes direitos passa pela oportunidade que é dada à criança de participar no processo investigativo não como objeto de estudo, mas como sujeito de investigação. Considerar a criança como participante, superando o paradigma que encara 0 adulto como superior e autoritário face à criança submissa e permissiva, traduz-se na consciencialização da multiplicidade de significados, interesses, valores e formas de expressão infantil (Soares, 2006). Cada pesquisa deve, assim, ser pensada tendo em conta este pressuposto. Na opinião de Soares (2006), é essencial que o pesquisador esteja alerta e seja criativo na definição da sua estratégia de investigação, de modo a valorizar a ação da criança como importante interveniente e parceira de todo o processo. Por outro lado, a adequação da pesquisa a este novo movimento deve ter em conta a coerência entre o contexto, os objetivos, os métodos, e os princípios éticos inerentes a todas as etapas (Alderson \& Morrow, 2011). Por estes motivos, em termos metodológicos, os autores defendem a adoção de técnicas aplicáveis a "populações 
tão singulares" (Javeau, 2005, p. 386), de âmbito qualitativo, como a realização de entrevistas, a etnografia ou a observação. A necessidade e a preocupação em desenvolver metodologias que permitam compreender melhor as experiências das crianças vão ganhando terreno nas investigações. A criança deixa de estar à margem para passar a ser entendida como parceira do processo de pesquisa (Gibson, 2012), autora e protagonista num cenário em que "ela e o pesquisador precisam se dar a conhecer mutuamente" (Delorme, 2008, p. 23).

\section{Apresentação do objeto de estudo e da opção metodológica}

Partindo dos pressupostos teóricos mencionados, este artigo pretende dar conta de uma das fases de trabalho empírico desenvolvida no âmbito de uma investigação de doutoramento, ainda a decorrer. Com o objetivo principal de compreender os significados e as emoções decorrentes da exposição das crianças às notícias, e as implicações desses sentidos para os modos de estar e de olhar o mundo por parte dos mais novos, o estudo teve como universo as crianças a frequentar $04^{0}$ ano do $1^{\circ}$ Ciclo do Ensino Básico (no ano letivo 2013/2014) das escolas do Concelho de Paredes, situado no norte do país. Combinando métodos quantitativos e qualitativos, numa primeira fase foram administrados inquéritos por questionário a 690 crianças com idades compreendidas entre os oito e os 12 anos. Numa segunda fase, que será objeto de atenção neste artigo, realizaram-se grupos de foco com crianças, selecionadas a partir da amostra do inquérito por questionário, com o propósito de corroborar resultados e de aprofundar relações sugeridas pela análise quantitativa. A escolha das turmas para a realização destes grupos foi feita junto dos professores que, durante a administração dos inquéritos por questionário, demonstraram recetividade e prontidão em providenciar as condições (espaciais e temporais, sobretudo) necessárias à boa condução dos grupos.

Foram conduzidos seis grupos de foco nas duas turmas do $4^{\circ}$ ano das escolas EB1 de Lage-Parada, inserida no Agrupamento de Escolas Daniel Faria-Baltar, e EB1/JI de Serrinha, do Agrupamento de Escolas de Vilela. No total, participaram 42 crianças - 22 raparigas e 20 rapazes - com idades compreendidas entre os nove e os 11 anos. A recolha dos dados decorreu nos dias 22 e 23 de Maio de 2014.

\section{Desafios na realização de grupos de foco com crianças e o recurso a novas ferramentas investigativas}

A realização de grupos de foco com crianças, enquanto método de recolha de dados na área das ciências sociais, conheceu uma expansão considerável durante a década de 90 não só como técnica complementar nas pesquisas, mas enquanto método em si mesmo (Morgan et al., 2002).

No entanto, o valor e as vantagens desta opção metodológica nem sempre foram reconhecidos. Como sublinha Gibson (2012), até aos anos 90 prevalecia um certo silenciamento e distanciamento das crianças nos estudos científicos, em parte devido à conceção que predominava sobre elas que as entendia como seres em devir, imaturas e incompetentes. Por isso, nas pesquisas de âmbito qualitativo, quando se recorria aos grupos de foco ou a entrevistas, os participantes eram, na maioria dos casos, adultos. Como consequência deste afastamento da criança enquanto 
informante privilegiada, pouco se sabia sobre a sua natureza, aquilo que pensava, os seus mundos e o modo como estava no mundo.

Diferentemente, a necessidade e a preocupação em desenvolver metodologias que permitissem chegar mais perto do olhar e das experiências dos mais novos, impôs-se no âmbito das investigações sociais. Ao mesmo tempo, esta nova consciência, a par da necessidade de aperfeiçoamento metodológico, suscita dúvidas, impõe desafios e especial cuidado a quem investiga, apenas superáveis pela disponibilidade e abertura de espírito que devem emergir em qualquer estudo deste tipo.

0 maior desafio metodológico desta investigação foi procurar adaptar a técnica clássica dos grupos de foco ao grupo de crianças que participaram no estudo. Sabíamos, pela experiência de condução de outros grupos de foco, que se recorrêssemos a esta técnica através dos moldes tradicionais - uma reunião informal, com os intervenientes dispostos em círculo, na qual é lançado o tema para discussão e colocadas várias questões pelo moderador - as crianças rapidamente revelariam sinais de cansaço e de distração, comprometendo a recolha dos dados e esta fase da investigação. Além disso, este formato não é fácil nem desejável para a maioria dos participantes (Gibson, 2012), fazendo com que estes deem respostas monossilábicas, especialmente quando as questões Ihes parecem pouco relevantes (Morgan et al., 2002). Como advoga Colucci (2007), os grupos de foco são um interessante método para a recolha de dados de natureza qualitativa, no entanto, exigem do investigador a procura por fórmulas que incentivem o interesse e o real contributo dos participantes na investigação. A autora, seguindo a linha de pensamento de Krueger - autor de referência no estudo dos grupos de foco - fala no desenvolvimento de "atividades" ou "exercícios" (Colucci, 2007, p. 5) que se tornem importantes complementos das questões a tratar. Gibson (2012, p. 157) chama-lhes "atividades estruturadas". Além de incentivarem à discussão e tornarem a experiência dos grupos mais interessante e apelativa para todos os envolvidos (Gibson, 2012), estas atividades são particularmente benéficas para os participantes que têm dificuldade em responder imediatamente às questões colocadas pelo investigador, já que lhes permitem ter mais tempo para responder ou produzir respostas mais completas. No caso particular das crianças e jovens, Colluci (2007) considera que a opção por estas atividades pode ajudar a ultrapassar as dificuldades causadas pelo aborrecimento e pela falta de motivação que estes participantes expressam ao longo do tempo de conversa, além de contribuir para superar o facto de estes grupos tendencialmente agirem e expressarem ideias e sentimentos diferentemente dos adultos.

Apesar de não ser nossa intenção proceder a uma descrição intensiva e detaIhada das propostas de atividades existentes em literatura sobre 0 assunto (Gibson, 2012; Darbyshire et al., 2005; Paquette et al., 2007; Morgan et al., 2002; Barker \& Weller, 2003; Colucci, 2007), deixamos alguns exemplos inspiradores deste trabaIho de investigação. Além destes, socorremo-nos de um conjunto de pesquisas desenvolvidas no âmbito de teses de doutoramento (Delorme, 2008; Monteiro, 2013; Brites, 2013; Pedrosa, 2013), por as mesmas providenciarem elementos úteis para esta fase do estudo, não apenas porque as idades dos participantes se aproximam, em alguns casos, das desta investigação, como também as temáticas trabalhadas dizem respeito às questões dos media e infância/adolescência. 
A forma, e não apenas o conteúdo, assume um lugar preponderante. Os autores propõem a realização de jogos que permitam a redução da ansiedade e um maior envolvimento entre os participantes e 0 dinamizador. Estes podem ser especialmente usados no início da atividade, no espaço de tempo dedicado à apresentação das crianças e do investigador. As pesquisas propõem a utilização de balões/bolas, que podem ser passados de participante em participante, ao mesmo tempo que cada um diz o seu nome (Monteiro, 2013; Morgan et al., 2002). É nesta fase que se promove, também, uma conversa mais informal e descontraída em que as crianças falam sobre si e a sua família e animais de estimação, sobre o que gostam de fazer nos tempos dedicados ao lazer, sobre os seus medos e desejos, etc. (Delorme, 2008). 0 dinamizador da atividade pode aproveitar este momento para introduzir 0 tema da discussão, pedindo para que as crianças falem livremente sobre o mesmo.

A fotografia, o desenho, o diário ou os exercícios escritos (como composições, textos legendados, etc.) constituem-se também como opções viáveis enquanto métodos alternativos e impulsionadores dos grupos de foco (Barker \& Weller, 2003; Morgan et al., 2002; Paquette et al., 2007). Em particular, o desenho tem-se revelado uma técnica recorrente e bem sucedida nos estudos, já que permite que a criança reflita sobre as suas próprias ideias sem a pressão do adulto e dos pares, é particularmente motivador e permite-lhe dar asas à imaginação. Embora de difícil e exigente análise e interpretação, o desenho traduz-se numa ferramenta valiosa especialmente quando é procedido por um momento de conversa e de debate em que os participantes falam sobre o que fizeram não apenas entre si, mas também com o investigador (Barker \& Weller, 2003; Delorme, 2008; Paquette et al., 2007). Delorme (2008) considera que é essencial para a validação das interpretações que as crianças falem sobre a atividade, neste caso, sobre o desenho que fizeram. Esta partilha permite perceber como se veem e aos restantes membros do grupo (ibidem) e, sobretudo, trata-se de um importante auxílio para o investigador no conhecimento das representações dos participantes. Ao mesmo tempo, ao conversarem as crianças afinam os seus conhecimentos e aprendem mais sobre aspetos dos seus mundos sociais (Mayall, 2001).

Esta partilha de informações é igualmente útil no caso da fotografia, enquanto interessante auxiliar da expressão de ideias, pensamentos e sentimentos. Brites (2013), na sua pesquisa sobre o lugar das notícias na construção da participação cívica e política dos jovens portugueses, apresentou aos participantes grupos de fotografias ligadas às temáticas em estudo (notícias, participação, género e emoções), pedindo que selecionassem dois ou três conjuntos e justificassem a escolha. Para a autora, trata-se não apenas de incentivar ao debate, mas de fazer com que os intervenientes participem efetivamente, se envolvam e proponham temas e outras questões. Há, também, investigadores que optam por pedir aos participantes para tirarem as fotografias. Essa opção depende dos propósitos do estudo e daquilo que se espera obter através da recolha dos dados. No final, é vital que os participantes falem sobre os motivos das suas escolhas, discutam e expliquem as fotografias (Barker \& Weller, 2003).

\section{Apresentação das atividades}

Tendo em vista os aspetos referenciados e a bibliografia apresentada, procuramos desenvolver os grupos de foco sob o formato de um conjunto de atividades 
estruturadas em que tivemos em conta, na sua elaboração, os objetivos da pesquisa, 0 uso destes grupos como forma complementar da análise quantitativa', e as características dos participantes.

Este trabalho enquadra-se também na educação para os media e na importância de as crianças desenvolverem competências críticas face às notícias e às representações do mundo nos media. Por esse motivo, pensamos as atividades pressupondo que as crianças pudessem, durante a realização dos grupos de foco, posicionar-se crítica e criativamente em torno da atualidade, através do contato com as notícias, da reflexão e do questionamento dos assuntos do dia, do debate em torno das escolhas dos jornalistas e da proposta de novas ideias sobre como poderia ser a informação ${ }^{2}$. Defendemos que é fundamental despertar as crianças para as questões da atualidade, permitindo que estas questionem e reflitam sobre os conteúdos que os media oferecem, e tenham oportunidade para os reelaborar de acordo com a sua visão do mundo.

No desenho das atividades, procurámos inspirar-nos noutros modelos e observações emergentes de trabalhos científicos nacionais e internacionais, os quais passamos a enumerar: Brites (2013), Monteiro (2013), Delorme (2008), Morgan et al. (2002), Paquette et al. (2007), Barker \& Weller (2003). Baseamo-nos, ainda, no projeto de investigação Navegando com o Magalhães: Estudo sobre o Impacto dos Media Digitais nas Crianças (PTDC/CCI-COM/101381/2008), desenvolvido no CECS, da Universidade do Minho. Estas pesquisas foram importantes para a estruturação das atividades realizadas, já que providenciaram, nuns casos, modelos de atividades que pudemos adaptar ao nosso estudo e, noutros, elementos que funcionaram como sugestões fundamentais à boa condução dos grupos de foco, como, por exemplo, a necessidade de incentivar as crianças a participar, o registo do momento de entrada no campo e de particularidades (como reações e comentários paralelos) que se considere importantes para a análise, o pedido para os participantes comentarem e confrontarem os argumentos, a criação de um ambiente descontraído e não intimidatório, etc.

Os grupos de foco foram dinamizados a partir das seguintes atividades:

\section{Atividade 1 - Descobrir a Atualidade}

Teve como principais objetivos: refletir sobre o modo como as crianças percecionam as notícias; compreender que tipo de imagens e emoções as crianças associam a determinados assuntos; refletir sobre os motivos que levam as crianças a interessar-se mais por determinados tópicos, em detrimento de outros; refletir sobre os interesses, motivações e expectativas das crianças face à informação.

Esta atividade iniciou-se com a apresentação aos participantes de um conjunto de notícias recortadas de jornais, tendo-lhes sido colocadas as seguintes questões: 0 que acham destas notícias? Há alguma coisa que vos chame a atenção? Porquê?

1 Antes de procedermos ao desenho das atividades, partimos da análise dos resultados obtidos através do inquérito por questionário para, a partir da mesma, aferirmos um conjunto de questões orientadoras dos grupos de foco. 0 objetivo foi obter uma representação dos aspetos a que tivemos que atender no momento de elaboração e concretização das atividades. Trata-se de uma espécie de estrela guia, essencial para esta fase do percurso.

2 Sublinhamos, no entanto, que não tivemos como finalidade avaliar competências de literacia mediática. 
Estes temas interessam-vos? Porquê? E conseguem lembrar-se de notícias que não vos interessem? Em seguida, divididas em grupos de dois ou três elementos, e com 0 auxílio de materiais (como cartolinas, lápis, cola, etc.) necessários à atividade, as crianças foram convidadas a selecionar uma das notícias inicialmente apresentadas e a refletir sobre os seguintes aspetos: quem produziu e com que propósito (informar, persuadir, entreter, vender); público a que se destina; contexto e características (como a escolha do título, das imagens e o seu impacto, etc.); emoções que provoca (alegria, medo, tristeza, nojo, etc.); que escolhas faria (o que a criança mudava, acrescentava, etc.). Por fim, convidou-se cada grupo a apresentar e a debater com os colegas as suas escolhas.

\section{Atividade 2 - Quem É Quem}

Esta atividade teve como propósitos: refletir sobre o lugar das notícias no conhecimento do mundo, por parte das crianças; refletir sobre o papel das notícias na sociedade e na forma como representam a realidade.

Inicialmente, apresentou-se aos participantes a edição diária de um jornal generalista nacional ${ }^{3}$, pedindo que 0 folheassem e comentassem o que iam lendo, de forma livre. Em seguida, convidou-se as crianças a elaborarem uma possível primeira página para 0 jornal, descrevendo as suas escolhas.

\section{Atividade 3 - Oficina dos Direitos}

Visou refletir sobre o modo como as crianças percecionam os seus direitos, em especial os direitos de participação (no âmbito pessoal e social mas, particularmente, na relação com os media), e que valor Ihes atribuem.

No começo da atividade, realizou-se uma breve exposição e explicação sobre os Direitos da Criança com o apoio de materiais (poster e flyers) cedidos pela Delegação Regional do Porto do Comité Regional para a UNICEF, e de um esquema elaborado por nós, em formato Power Point. Durante esta apresentação, foi pedido às crianças que lessem em voz alta os seus direitos e que comentassem em torno de algumas questões, como por exemplo: 0 que é mais importante, direitos ou responsabilidades? Quais são os direitos mais importantes? E ser livre, ter direito à liberdade quer dizer o quê? No final da atividade, apresentou-se às crianças excertos de notícias. Umas, produzidas e transmitidas por noticiários de canais televisivos generalistas nacionais4; ${ }^{4}$ outras, direcionadas exclusivamente aos públicos infantis ${ }^{5}$. Durante esta exposição, gerou-se 0 debate entre o grupo, que ia sendo feito de modo livre

3 Na EB1 de Lage-Parada, apresentou-se às crianças o Jornal de Notícias, enquanto o Público foi o jornal escolhido para desenvolver a atividade com a turma da EB1/JI de Serrinha.

4 Para esta atividade, foram escolhidas duas notícias transmitidas pelos canais RTP1 e SIC. Uma versava sobre 0 aumento de casos de tráfico de seres humanos, particularmente, de crianças; a outra dizia respeito a pinturas realizadas por crianças hospitalizadas.

5 As notícias apresentadas foram retiradas do site Recontando.com (http://www.recontando.com/ v2/), um portal criado pela jornalista brasileira Simone Ronzani com o propósito de tornar as notícias mais atrativas e de fácil compreensão para as crianças, o seu principal público-alvo. As notícias apresentadas versaram sobre os seguintes acontecimentos: incêndio trágico resultante de explosão em clube noturno de Santa Maria, no Brasil; trabalho infantil; manifestações no Rio de Janeiro. 
e espontâneo; no entanto, em alguns momentos foi conduzido por nós através da colocação de questões previamente definidas para esta atividade, como por exemplo: As crianças têm direitos em relação aos media? Quais? O que acham sobre as crianças aparecerem nas notícias? E participarem nas notícias?

Todas as atividades iniciaram com uma apresentação entre nós e as crianças, durante a qual quisemos criar um ambiente informal e descontraído de modo a colocar os participantes à vontade. Este foi também o momento escolhido para as crianças falarem sobre o que gostam de fazer nos tempos livres e de lazer. Foi-lhes igualmente pedido que escolhessem o nome pelo qual gostariam de ser tratadas durante as atividades e que, consequentemente, as iria identificar no trabalho final. Além desta apresentação, realizou-se sempre um momento introdutório que consistiu numa pequena conversa sobre os media e as notícias, de modo a introduzir 0 tema dos grupos de foco e a familiarizar as crianças com o mesmo.

\section{Dinâmica dos grupos}

No Quadro I apresenta-se o desenho da amostra escolhida para a implementação dos seis grupos de foco realizados.

\section{Quadro I - Desenho dos grupos de foco (GF)}

\begin{tabular}{|c|c|c|}
\hline & $\begin{array}{c}\text { EB1 de Lage - Parada } \\
22 \text { de Maio de } 2014\end{array}$ & $\begin{array}{l}\text { EB1/Jl de Serrinha } \\
23 \text { de Maio de } 2014\end{array}$ \\
\hline $\begin{array}{c}\text { Atividade } 1 \\
\text { DESCOBRIR A } \\
\text { ATUALIDADE }\end{array}$ & $\begin{array}{c}\text { GF2 } \\
3 \text { Raparigas } \\
3 \text { Rapazes } \\
\text { 9-11 anos }\end{array}$ & $\begin{array}{c}\text { GF4 } \\
\text { 4 Raparigas } \\
\text { 4 Rapazes } \\
\text { 9-10 anos }\end{array}$ \\
\hline $\begin{array}{c}\text { Atividade } 2 \\
\text { QUEM É QUEM }\end{array}$ & $\begin{array}{c}\text { GF1 } \\
\text { 3 Raparigas } \\
\text { 4 Rapazes } \\
\text { 9-10 anos }\end{array}$ & $\begin{array}{c}\text { GF5 } \\
\text { 5 Raparigas } \\
\text { 3 Rapazes } \\
\text { 9-10 anos }\end{array}$ \\
\hline $\begin{array}{c}\text { Atividade } 3 \\
\text { OFICINA DOS DIREITOS }\end{array}$ & $\begin{array}{c}\text { GF3 } \\
\text { 4 Raparigas } \\
\text { 3 Rapazes } \\
\text { 9-10 anos }\end{array}$ & $\begin{array}{c}\text { GF6 } \\
\text { 4 Raparigas } \\
\text { 3 Rapazes } \\
\text { 9-10 anos }\end{array}$ \\
\hline
\end{tabular}

Os participantes, as atividades e as notícias: De modo geral, as crianças mostraram-se sempre recetivas à realização das atividades sugeridas, demonstrando curiosidade sobre os jornais e as notícias que disponibilizamos para o debate e a realização das propostas mais práticas e interventivas. Além de manifestarem conhecimento sobre alguns dos jornais apresentados, como o Jornal de Notícias, as crianças demonstraram estar a par da atualidade e de alguns acontecimentos 
que Ihes chamaram muito a atenção, como o caso de uma notícia sobre um homicida - Manuel Baltasar (apelidado de Manuel "Palito") - que teria matado duas familiares, e ferido a ex-mulher e a filha, tendo estado fugido das autoridades durante 34 dias. Este acontecimento terá tido um elevado impacto nas crianças, de tal modo que estas demonstraram saber os pormenores da notícia, desde o número de mortes/feridos causadas pelo homicida, as vezes que teria conseguido escapar da polícia, os nomes dos locais por onde teria passado, aos pormenores relativos à ocorrência das mortes e das agressões. Por esse motivo, durante a Atividade $\mathbf{2}$, em que as crianças foram convidadas a realizar uma primeira página de jornal, além de outros assuntos do seu interesse (como a educação, o desporto e o meio ambiente), em ambos os grupos de foco em que a atividade se concretizou, a notícia do Manuel "Palito" foi a escolhida para o centro da página, por forma a servir de "aviso" ao público. Pelo contrário, em nenhuma das páginas criadas houve espaço para notícias sobre política e economia, já que as crianças consideram estes temas repetitivos e enfadonhos. A realização desta atividade permitiu, ainda, confirmar 0 interesse das crianças pelas imagens, em detrimento do texto, uma vez que, na sua opinião, permitem compreender melhor os acontecimentos. No final desta atividade, os participantes atribuíram nomes às duas primeiras páginas de jornal criadas a pensar nos públicos infantis: Importância do Mundo (GF5) - porque se refere e ajuda a conhecer o que se passa no mundo - e Jornalunos (GF1) - porque foi feito por alunos - foram as suas escolhas.

Figura I - Primeiras páginas de jornais criadas pelas crianças

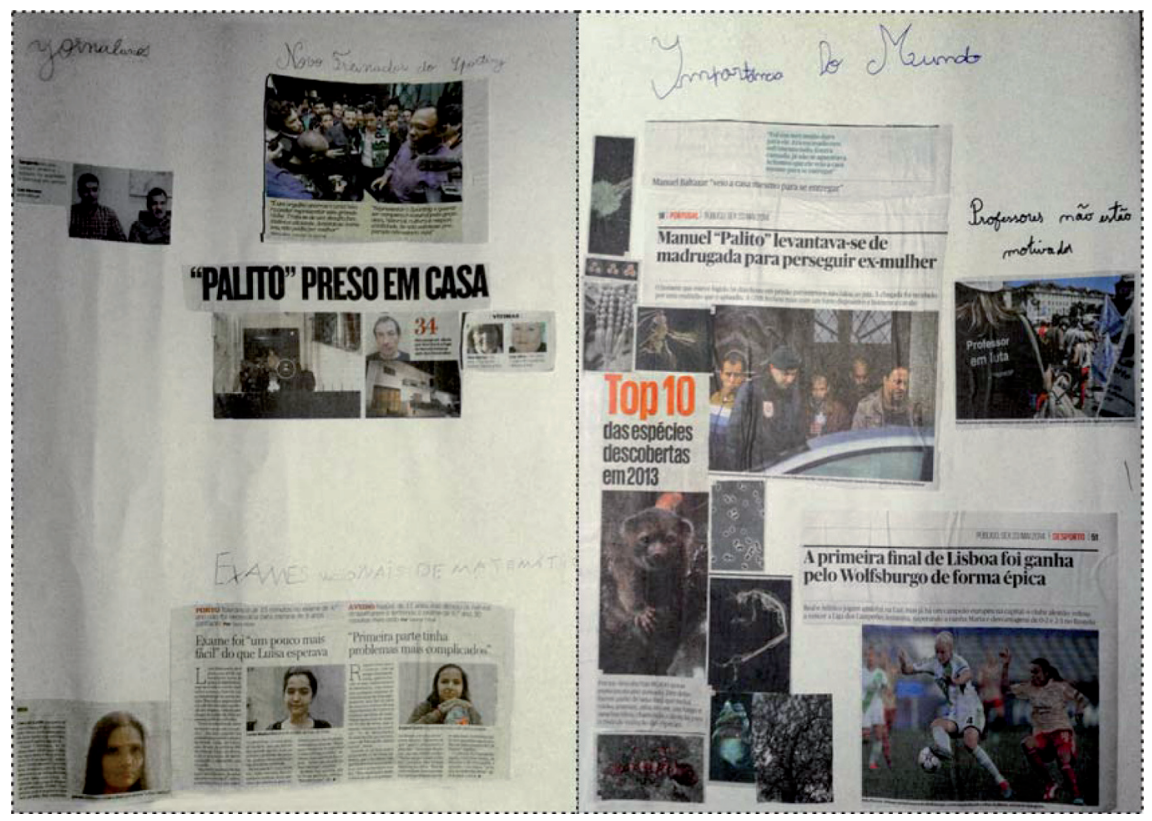


As atividades, além de envolverem as crianças nos grupos de foco, despertaram o seu interesse para as notícias e levaram-nas a questionar, em certos momentos, as opções dos jornalistas: como o caso de uma criança que não compreendia porque é que os jornalistas estão sempre a falar sobre notícias tristes, negativas e aborrecidas; ou de uma outra que aconselhou estes profissionais a pensarem mais nos públicos infantis e nos seus temas de interesse.

Por sua vez, a Atividade 3 deu oportunidade para que as crianças refletissem sobre os seus direitos, em especial os direitos com implicações para a relação com os media. As crianças questionaram a possibilidade de uma participação mais ativa nos media, em que pudessem intervir como comentadoras das notícias, apresentadoras ou repórteres, considerando que poderia ser um importante passo no sentido de aumentarem o seu interesse pela atualidade e pelos assuntos da sociedade.

Além de todos estes aspetos, durante 0 decorrer das atividades, fomo-nos apercebendo da importância que os mais novos atribuem ao facto de os seus pontos de vista serem valorizados e considerados pelos adultos. As crianças desejam envolver-se mais e debater sobre todos os assuntos. No entanto, sublinham que as suas opiniões são, muitas vezes, ignoradas, ainda que se trate de questões em que são diretamente implicadas. No caso da atualidade, admitem que a desconsideração para com as suas ideias sobre assuntos sérios, como a política e a economia, as leva a afastar-se destes temas, embora reconheçam a sua importância para a sociedade. De modo geral, as crianças desejam ser vistas como verdadeiros públicos pelas empresas mediáticas, e não como uma audiência desinteressada e "à parte" dos assuntos da atualidade. Consideram que as notícias dizem respeito a todos os cidadãos e que têm o direito de estar informadas sobre o que se passa, e de aceder a formatos e a conteúdos informativos mais adequados aos seus interesses e capacidades.

Espaço: As sessões decorreram, em ambas as escolas, em espaços destinados à leitura e ao convívio, longe da sala de aula onde habitualmente imperam relações de poder (Darbyshire et al., 2005) que desejávamos evitar. Apesar de, em ambos os casos, ainda nos encontrarmos dentro do recinto escolar, o facto de as sessões terem decorrido fora do espaço formal da sala de aula foi, a nosso ver, vantajoso na medida em que permitiu uma maior descontração dos participantes e a perceção de que as atividades se encontravam alheias aos habituais exercícios das matérias lecionadas. Ao mesmo tempo, com a ausência das professoras, evitamos que as atividades se pudessem tornar intimidatórias, como propõem Morgan et al. (2002), tentando que as sessões fossem mais interativas e produtivas (Darbyshire et al., 2005).

Tempo: Não existe unanimidade na literatura no que se refere ao tempo ideal para a realização destas sessões. Há autores, como Morgan et al. (2002), que defendem que ao fim de 45 minutos, sobretudo quando os participantes são crianças dos sete aos 11 anos de idade, a qualidade das respostas começa a deteriorar-se e que, por esse motivo, o ideal será realizar sessões de 20 minutos com intervalos para descanso. Na sua investigação recente com crianças com idades compreendidas entre os 5 e os 11 anos, Pedrosa (2013) realizou grupos de foco que duraram entre 60 a 90 minutos. Como a autora reconhece, não existe um tempo ideal para concretizar estas reuniões, sendo fundamental adaptar os critérios clássicos definidos para esta técnica qualitativa aos objetivos e necessidades do estudo (idem, 
p. 259). As sessões que realizamos duraram entre 60 a 90 minutos, oscilando este tempo de acordo com as atividades realizadas e a intensidade da participação das crianças. No primeiro grupo de foco, desenvolvido com sete participantes da escola EB1 de Lage-Parada, a duração da sessão excedeu os 90 minutos, já que as crianças, no final, manifestaram vontade em realizar um desenho sobre a atividade. Noutros casos, como na sessão dinamizada com o GF3, o tempo ultrapassou em poucos segundos os 60 minutos pelo facto de as crianças terem participado menos, comparativamente a outros grupos. Concluímos, assim, que a duração das sessões variou conforme 0 caráter das atividades promovidas e 0 grau de envolvimento dos participantes. As Atividades $\mathbf{1}$ e $\mathbf{2}$ superaram, em termos de tempo, a Atividade 3, pois pressupuseram uma maior participação, em termos práticos, das crianças, enquanto esta última era mais dedicada à exposição e ao debate. Foi sobretudo no decorrer das Atividades 1 e $\mathbf{2}$ que encontramos uma das principais dificuldades de conduzir grupos de foco com crianças pequenas, uma vez que estas, ao longo do tempo, foram demonstrando sinais de inquietação e de pouca concentração, empenhando-se menos no final das atividades. Nestes casos, como desejávamos continuar com a recolha de dados e, ao mesmo tempo, tornar a experiência de envolvimento nos grupos o mais agradável possível para as crianças, optamos por não fazer imposições, mediando as intervenções de modo mais ligeiro, deixando que as crianças tivessem mais liberdade na sua participação. Apesar de termos tido sempre em mente os propósitos do estudo, temos consciência de que esta opção poderá ter limitado a obtenção de informaç̧ões relevantes sobre questões previamente definidas.

A investigadora e os participantes: Existem muitas "receitas" sobre como 0 investigador/dinamizador dos grupos de foco deve preparar e moderar estas sessões. Krueger (1998), na obra Moderating Focus Groups, propõe alguns desses princípios, dando conta dos passos a tomar na preparação das reuniões, dos pontos merecedores de atenção durante as mesmas, das qualidades e características pessoais do dinamizador, dos problemas a que é necessário atender e esforçar-se por ultrapassar não apenas durante as sessões, como também no momento de análise dos dados, entre outros aspetos. Concordamos com os vários pontos apresentados pelo autor, e pudemos experienciá-los em vários momentos destas reuniões, no entanto, consideramos que a verdadeira aprendizagem se fez pelo terreno, nos momentos de partilha, nas conversas (muitas vezes paralelas) que se foram gerando entre nós e as crianças, nos constrangimentos surgidos aqui e ali e, até mesmo, nos momentos em que, chegados esgotados das reuniões, nos sentávamos a registar e a assimilar notas de campo que sabíamos serem essenciais para a análise da informação recolhida.

No que se refere à preparação das sessões, tivemos sempre o cuidado de organizar todo o material necessário ao desenvolvimento das atividades, assim como criamos um guião que pudesse servir de auxiliar durante as reuniões. Além da descrição das atividades, do mesmo constava um conjunto de questões preparadas de modo a evitar a dispersão dos comentários dos participantes e a orientar as suas intervenções para os assuntos pretendidos. Apesar de termos intervindo o mínimo possível, já que o que se pretendia era dar um certo nível de liberdade aos participantes, temos consciência de que sobretudo por se tratar de crianças a frequentar 
a escola primária, deve existir algum grau de direção na moderação. 0 nosso papel foi, assim, o de provocar o debate, lançando os temas para discussão, ao mesmo tempo que iam sendo articulados com as atividades, e intervir sempre que consideramos oportuno, particularmente através do lançamento das questões previamente definidas. No papel de moderadores, íamos, certas vezes, questionando o nosso lugar, sobretudo nos casos em que nos deparamos com grupos heterogéneos de participantes muito faladores em contraste com crianças mais tímidas e introvertidas. Nestas situações, não queríamos perder a riqueza das intervenções daqueles que pareciam querer dominar toda a conversa, pelo que optamos por deixá-los falar, ao mesmo tempo que incentivamos os restantes a participar, salientando o valor e a importância das suas opiniões.

Outro dos pontos que nos parece importante salientar traduz-se no facto de, desde 0 início, termos clarificado que não existia qualquer tipo de imposição para as crianças participarem. Apesar de no momento de entrega dos pedidos de consentimento informado, termos referido que as crianças apenas interviriam nas atividades mediante a sua vontade, fizemos questão de, em cada sessão, voltar a relembrá-las desse facto. Não queríamos que se sentissem obrigadas a algo, pelo que consideramos que foi um desafio mantê-las atentas, ativas e curiosas durante as reuniões. Todas as crianças quiseram participar e não houve casos de desistências, apesar de saberem que tinham essa opção. No final das sessões, colocámos várias questões às crianças: 0 que acharam desta experiência? Do que gostaram mais? Gostariam de repetir? Como foi a experiência de participar e pensar sobre as notícias? Este feedback foi fundamental não apenas para estarmos atentos ao que poderia ser melhorado nas reuniões seguintes e obtermos as perceções dos nossos informantes acerca das sessões, como também para, enquanto investigadores, podermos aprender com aqueles que aceitaram ceder-nos um pouco das suas experiências e pontos de vista.

\section{Notas conclusivas}

As atividades pensadas para dinamizar os grupos de foco foram essenciais para a riqueza das intervenções das crianças durante as reuniões, e o seu envolvimento nas questões da atualidade. Através dos exercícios propostos, as crianças puderam questionar e refletir sobre os acontecimentos do mundo, revelando as suas representações e emoções sobre as notícias. As atividades permitiram, ainda, colocar as crianças no lugar de produtoras da informação, através da criação de uma página de jornal, possibilitando um maior conhecimento dos seus interesses e das suas escolhas, e alertando para a necessidade de se repensar os conteúdos e os formatos dos produtos informativos disponibilizados pelos media. Além disso, a realização dos grupos de foco com os públicos infantis chamou a atenção para a necessidade de se considerar os seus pontos de vista sobre assuntos que a todos dizem respeito. As crianças estão atentas às notícias e reconhecem que estas são importantes veículos para o conhecimento e a interpretação do mundo. No entanto, admitem que há certas notícias que as chocam e perturbam. Por estes motivos, é necessário que haja um esforço no sentido de promover competências críticas que Ihes permitam compreender melhor estes assuntos e saber lidar com as emoções resultantes da exposição aos mesmos. Com origem, particularmente, nos Estados 
Unidos, e replicados noutros pontos do mundo, há programas de literacia para as notícias (como o The Powerful Voices for Kids, o Center for News Literacy, o News Trust, ou o The News Literacy Project) que providenciam métodos úteis que cativam os mais novos e que os ajudam a desenvolver as suas competências de pensamento crítico, tornando-os mais aptos para compreender, apreciar e criticar as notícias (Hobbs, 2013).

Tendo em vista estas questões, os investigadores poderão apostar em ferramentas investigativas que permitam resgatar o olhar da criança sobre as notícias e 0 mundo e, ao mesmo tempo, colocá-las numa relação crítica e criativa em torno destes assuntos. Concordamos com Jacques Gonnet (2007), quando 0 autor defende a importância de os mais novos aprenderem a utilizar e a decifrar os meios de comunicação. Para isso, seria importante posicionar estes públicos numa relação crítica com os media - preventiva (contra formas de influência e manipulação mediática) e criadora (apropriação do máximo de informações a partir da sua própria visão sobre qualquer tipo de documento mediático) - colocando-os em ação num processo de transformação e de aprendizagem em que se evidencia uma iniciação à pluralidade de pensamento e uma responsabilidade ativa.

Consideramos ainda que, sendo este estudo pioneiro em Portugal, seria importante que o mesmo servisse de base a outras pesquisas que optassem por metodologias qualitativas enquanto técnica autossuficiente. Estamos certos que um estudo longitudinal que recorresse a este método iria aproximar-nos, enquanto adultos e investigadores, das verdadeiras e profundas experiências e mundos de vida das crianças e, mais do que isso, melhorar o conhecimento sobre o modo como os acontecimentos das notícias têm real impacto nos seus trajetos e aprendizagens.

\section{Financiamento}

Fundação para a Ciência e a Tecnologia, no âmbito do QREN-POPH (Tipologia 4.1 - Formação Avançada), comparticipado pelo Fundo Social Europeu e por fundos nacionais do Ministério da Educação e Ciência. Referência da bolsa: SFRH/ $\mathrm{BD} / 80918 / 2011$.

\section{Referências}

Alderson, P. \& Morrow, V. (2011). The Ethics of Research with Children and Young People: A Practical Handbook. Los Angeles: Sage.

Alon-Tirosh, M. \& Lemish, D. (2014). "If I Was Making the News": What do Children Want From News?. Participations-Journal of Audience \& Reception Studies, 1, 108-128.

Barker, J. \& Weller, S. (2003). "Is it Fun?" Developing Centred Research Methods. International Journal of Sociology and Social Policy, 1(2), 33-57.

Brites, M. J. (2013). 0 Papel das Notícias na Construção da Participação Cívica e Política dos Jovens em Portugal: Estudo de Caso Longitudinal (2010-2011). Tese de doutoramento. Faculdade de Ciências Sociais e Humanas, Universidade Nova de Lisboa, Lisboa, Portugal.

Buijzen, M., Molen, J. \& Sondji, P. (2007). Parental Mediation of Children`s Emotional Responses to a Violent News Event. Communication Research, 2, 212-230. 
Buckingham, D. (2000). The Making of Citizens: Young People, News and Politics. Londres: Routledge.

Carter, C., Davies, M. M., Allan, S. \& Mendes, K. (2009). What Do Children Want from BBC? Children's Content and Participatory Environments in an Age of Citizen Media. Acedido a 14 de maio de 2014, em http://www.bbc.co.uk/blogs/legacy/knowledgeexchange/ cardifftwo.pdf

Colucci, E. (2007). "Focus Groups Can Be Fun": The Use of Activity Oriented Questions in Focus Groups Discussions. Qualitative Health Research, 10, 1422-1433.

Condeza, R., Bachmann, I. \& Mujica, C. (2014). News Consumption among Chilean Adolescents: Interest, Motivations and Perceptions on the News Agenda. Comunicar, 43, 55$-64$.

Darbyshire, P, Macdougall, C. \& Achiller, W. (2005). Multiple Methods in Qualitative Research with Children: More Insight or Just More?. Qualitative Research, 4, 417-436.

Delorme, M. I. C. (2008). Domingo é Dia de Felicidade: As Crianças e as Notícias. Tese de doutoramento, Centro de Teologia e Ciências Humanas da PUC-Rio, Pontifícia Universidade Católica do Rio de Janeiro, Rio de Janeiro, Brasil.

Delorme, M. I. C. (2013). As Crianças e as Notícias da Televisão. Educação em Revista,1, 205-223.

Fernandes, N. (2005). Infância e Direitos: Participação das Crianças nos Contextos de Vida: Representações, Práticas e Poderes. Tese de doutoramento, Instituto de Estudos da Criança, Universidade do Minho, Braga, Portugal.

Galera, M. (2000). Televisión, Violencia e Infancia: El Impacto de los Medios. Barcelona: Editorial Gedisa.

Galera, M. \& Pascual, R. (2005). La Televisión como Agente Socializador ante el 11-M: Percepciones y Reacciones de la Infancia frente a los Atentados Terroristas, Zer, 10, 173-189. Gibson, J. (2012). Interviews and Focus Groups with Children: Methods that Match Children's Developing Competencies. Journal of Family Theory and Review, 4, 148-159.

Gonnet, J. (2007). Educação para os Media: As Controversas Fecundas. Porto: Porto Editora.

Hobbs, R. (2013). Media Literacy. In D. Lemish (Ed.), The Routledge International Handbook of Children, Adolescents and Media (417-424). Londres \& Nova lorque: Routledge.

Janzen, M. D. (2008). Where is The (Postmodern) Child in Early Childhood Education Research?. Early Years: An International Journal of Research and Development, 3, 287$-298$.

Javeau, C. (2005). Criança, Infância(s), Crianças: Que Objetivo Dar a Uma Ciência Social da Infância?. Educação e Sociedade, 91, 379-389.

Kotilainen, S. (ed.) (2011). Children's Media Barometer 2012: The Use of Media Among 0-8 Years Old in Finland. Helsinki: Finnish Society on Media Education.

Krueger, R. (1998). Moderating Focus Groups. Thousand Oaks: Sage.

Lacave, T. (2011). El Lugar de la Familia en el Processo de Recepción Televisiva Infantil. In

P. F. Martínez (Ed.), Los Niños y el Negocio de la Televisión: Programación, Consumo y Lenguage (31-65). Zamora: Comunicación Social. 
Ladavéze, L. (2012). La Investigación sobre Comunicación e Infancia. In A. G. Jiménez (Ed.), Comunicación, Infancia y Juventud. Barcelona: Editorial UOC.

Lazo, C. (2005). Agentes Mediadores y Responsables del Consumo Infantil de Televisión: Familia, Escuela y Medios de Comunicación. Revista Comunicación y Hombre, 1, 19-34. Marôpo, L. (2013). Jornalismo e Direitos da Criança: Conflitos e Oportunidades em Portugal e no Brasil. Coimbra: MinervaCoimbra.

Marôpo, L. (2014). Identidade e Estigmatização: As Notícias nas Percepções de Crianças e Jovens de um Bairro de Realojamento. Análise Social, 1, 104-127.

Mayall, B. (2001). Conversations with Children: Working with Generational Issues. In P. Christensen \& A. James (Ed.), Research with Children: Perspectives and Practices (120-135). London: Routledge.

Moinian, F. (2009). "I'm Just Me!": Children Talking Beyond Ethnic and Religious Identities. Childhood, 1, 31-48.

Monteiro, A. F. C. (2013). "Temé de Ser de Mim": Novas Tecnologias, Risco e Oportunidades na Perspetiva das Crianças. Tese de doutoramento, Instituto de Educação, Universidade do Minho, Braga, Portugal.

Morgan, M., Gibbs, S., Maxwell, K. \& Britten, N. (2002). Hearing Children`s Voices: Methodological Issues in Conducting Focus Groups with Children Aged 7-11 Years. Qualitative Research, 1, 5-20.

Paquette, K. R., Fello, E. S. \& Jalongo, R. M. (2007). The Talking Drawings Strategy: Using Primary Children's Illustrations and Oral Language to Improve Comprehension of Expository Text. Early Childhood Education Journal, 1, 65-73.

Pedrosa, L. P. (2013). Proceso de Socialización y Cine de Animación de Disney y Pixar: Estudio del Tratamiento y la Recepción de los Conflictos Emocionales en la Audiencia de 5 a 11 años. Tese de doutoramento, Facultad Ciencias de la Información, Universidad Complutense Madrid, Madrid, Espanha.

Richert, R., Robb, M. \& Smith, E. (2011). Media as Social Partners: The Social Nature of Young Children's Learning from Screen Media. Child Development, 1, 82-95.

Sarmento, M. (2004). As Culturas da Infância nas Encruzilhadas da Segunda Modernidade. In M. Sarmento \& A. B. Cerisara (Eds.), Crianças e Miúdos: Perspectivas Sociopedagógicas da Infância e Educação (9-34). Porto: Asa.

Setton, M. (2002). Família, Escola e Mídia: Um Campo com Novas Configurações. Educação e Pesquisa - Revista da Faculdade de Educação da USP, 1, 107-116.

Soares, N. (2006). A Investigação Participativa do Grupo Social da Infância. Currículo sem Fronteiras, 1, 25-40.

Thoman, E. \& Jolls, T. (2004). Media Literacy: A National Priority for a Changing World. American Behavioral Scientist, 1, 18-29. 